\title{
A multicomponent diffusion model for the prediction of microstructural evolution in coated Ni-based superalloy systems
}

\author{
M. S. A. Karunaratne ${ }^{a}$, S. L. Ogden ${ }^{a}$, S. D. Kenny ${ }^{\mathrm{b}}$ and \\ R. C. Thomson ${ }^{\mathrm{a}}$ \\ anstitute of Polymer Technology and Materials Engineering \\ ${ }^{\mathrm{b}}$ Department of Mathematical Sciences, \\ Loughborough University, Loughborough LE11 3TU, United Kingdom.
}

\begin{abstract}
A multi-component diffusion model which is capable of simulating the evolution of microstructure of a coated nickel based superalloy system has been developed. The key components of this model are a one-dimensional finite-difference based diffusion solver to calculate the distribution of alloying elements, a power-law based growth rate model for predicting surface oxidation and a thermodynamic equilibrium calculation routine for determining the phase evolution with time and space within the substrate-coating system. In addition to forecasting the evolution of concentration and phase profiles in the system after a given thermal history, the model is capable of estimating the losses due to oxidation and the likely remaining life of the coating based on a concentration and/or phase fraction dependent failure criteria. The phase constitution and concentration profiles predicted by the model has been compared with an experimental CoNiCrAlY coated CMSX-4 system which has been aged for times up to $10000 \mathrm{~h}$ at 850,950 and $1050^{\circ} \mathrm{C}$, and many features observed experimentally can be predicted by the model. The model is expected to be useful both for assessing microstructural evolution of coated turbine blade systems, and also as a tool for designing new coated alloy systems.
\end{abstract}

\section{Introduction}

Operating temperatures within gas turbine engines are continuously being increased to keep pace with the desire for increased efficiency. The combination of these high temperatures and aggressive environments leads to increased rates of oxidation and hot corrosion attack upon the gas turbine components, which can significantly degrade their mechanical properties. It is therefore necessary to have sufficient oxidation and corrosion resistance at high temperatures in order to provide a satisfactory component life. In most industrial turbines, Ni-based superalloy components such as turbine blades and vanes are typically protected by MCrAlY coating systems ( $\mathrm{M}$ being Ni and/or Co). Coatings attain their protective action by reacting with oxygen present in the working environment. This interaction with oxygen forms dense, adherent oxide scales on the 
surface of the coating which as a result, inhibits further losses due to oxidation. To form this dense oxide layer the coating needs to be rich in elements that readily form protective oxide scales such as $\mathrm{Al}$ and $\mathrm{Cr}$, and therefore the life of the coating is related to its ability to form the protective scales and/or replace the scale as and when required. The oxide scale may suffer periodic damage (spallation) due to the stresses induced by thermal cycling; however, the scale can be restored by further oxidation as long as there are sufficient scale forming elements remaining in the coating. The efficiency of this healing process diminishes as the reservoir of protective scale formers, mainly $\mathrm{Al}$ in the coating, depletes over time. Aluminium in the coating is lost both due to its consumption by the oxide scale and interdiffusion with the substrate. A critical Al content in the coating can be defined to indicate the useful life of the coating. This critical $\mathrm{Al}$ content could indicate the time at which less protective oxides are able to form on the surface or indeed a time at which the coating should be stripped from the component and a new coating applied.

The differences in chemical composition between the coating and substrate promote interdiffusion of chemical elements across the coating/substrate interface. Modern single crystal superalloys contain a multitude of heavy elements such as Co, Ta, Hf, W, Re and Mo, and because their compositions are optimised primarily for high creep strength, the $\mathrm{Al}$ and $\mathrm{Cr}$ concentrations are kept lower than the desirable levels for prolonged oxidation resistance. The overlay coatings on the other hand have higher levels of these latter elements, and since their major function is surface protection, they contain a smaller number of heavy elements compared to substrate alloys. Consequently, these large differences in compositions between the coating and base metal cause significant interdiffusion across the interface coating/substrate.

MCrAlY coatings can typically consist of a mixture of $\beta(\mathrm{NiAl}), \gamma^{\prime}\left(\mathrm{Ni}_{3} \mathrm{Al}\right)$ and $\gamma(\mathrm{Ni})$ phases, depending on the chemical composition and temperature. The depletion of $\mathrm{Al}$ from the coating by the formation and growth of the oxide scale at the coating surface and the interdiffusion with the substrate, results in the depletion of the $\beta$-NiAl phase, which gradually transforms to a less Al-rich $\gamma^{\prime}-\mathrm{Ni}_{3} \mathrm{Al}$ and finally to a $\gamma$-Ni solid solution. On the other hand, single crystal Ni-based superalloys are characterised by a two phase microstructure consisting of a $\gamma$ matrix and high volume fractions of the $\gamma^{\prime}$ phase. The interdiffusion of elements across the coating/substrate interface can, however, result in an interdiffusion zone which is characterised by the area at the interface affected by the interdiffusion of elements, resulting in a distinct microstructure unlike that of the coating and/or substrate. This can also contain intermetallic TCP phases such as $\sigma, \mu$ and $P$ phase, together with numerous carbides, including $\mathrm{MC}$ and $\mathrm{M}_{23} \mathrm{C}_{6}$ carbides.

A complete understanding of the diffusion assisted degradation processes and the microstructural changes that take place within the coating, interdiffusion zone and substrate material is crucial in order to develop more accurate life prediction procedures for coatings and coated Ni-based superalloys. Modelling of these diffusion processes which occur during service can be an important tool to predict coating and substrate degradation as a function of time and operating temperature. This can be a significant 
advantage for the estimation of long term component performance, and also for the selection of optimum coating/substrate combinations.

It is important for any model dealing with microstructure evolution in coated superalloy systems to be able to simulate the oxidation, interdiffusion and phase stability simultaneously because these phenomena are all interlinked. Previous modelling efforts have been concentrated on limited systems. For example the work by Nesbitt [1] was on the ternary system $\mathrm{Ni}-\mathrm{Cr}-\mathrm{Al}$, and the models did not take either the phase constitution or diffusion in precipitate phases into account. A recent paper [2] which utilizes the software package DICTRA [3] takes multicomponent diffusion into account but it deals with oxidation in a limited manner, and does not explicitly treat diffusion in phases other than the $\gamma$ matrix.

The first part of this paper presents the details of the modelling approach, and the second part compares the predictions of the model with the experimental observations. Simulations were performed at 850,950 and $1050{ }^{\circ} \mathrm{C}$ for times up to $10000 \mathrm{~h}$ for a NiCoCrAlY based overlay coating on a CMSX4 substrate.

\section{Coupled Thermodynamic and Kinetic Model}

Due to the planar nature of the system a coated superalloy can be approximated by a one-dimensional model. Within this investigation the aim was to develop a onedimensional model to predict the concentration profiles and in turn, phase constitution associated with the oxidation and interdiffusion that occurs in coated superalloys. This model can therefore act as a 'time temperature recorder', to allow the prediction of the effective operating temperature of a component and as a result (in combination with other information such as operating stress) estimate its remaining life in service. Due to the complexities of the problem, a numerical solution scheme employing finite difference (F-D) techniques was implemented.

\subsection{Diffusion model}

For a multicomponent system with $n$ elements, the diffusion of a species can be mathematically described by means of Fick's First Law of diffusion $[4,5]$ :

$$
J_{i}=-\sum_{j=1}^{n-1} \tilde{D}_{i j}^{n} \frac{\partial C_{j}}{\partial x}
$$

where $i$ and $j$ are diffusing components and $J_{i}$ is the flux of element $i$. The interdiffusion coefficient matrix $\tilde{D}_{i j}^{n}$, is expressed in relation to a solvent $n$, in this case element $\mathrm{Ni}$, and $C_{j}$ is the concentration of element $j$. Furthermore, the time dependence of concentration of a species is given by Fick's Second Law of diffusion: 


$$
\frac{\partial C_{i}}{\partial t}=\sum_{j=1}^{n-1} \frac{\partial}{\partial x}\left(\tilde{D}_{i j}^{n} \frac{\partial C_{j}}{\partial x}\right)
$$

where $x$ and $t$ are the diffusion distance and time respectively. This equation can be expanded when concentration dependent interdiffusion coefficients are taken into account:

$$
\frac{\partial C_{i}}{\partial t}=\sum_{j=1}^{n-1}\left\{\tilde{D}_{i j}^{n} \frac{\partial^{2} C_{j}}{\partial x^{2}}+\left[\sum_{k=1}^{n-1} \frac{\partial}{\partial C_{k}}\left(\tilde{D}_{i k}^{n} \frac{\partial C_{k}}{\partial x}\right)\right] \frac{\partial C_{j}}{\partial x}\right\}
$$

However, if the diffusion coefficients are constant the following simplification is possible:

$$
\frac{\partial C_{i}}{\partial t}=\sum_{j=1}^{n-1} \tilde{D}_{i j}^{n} \frac{\partial^{2} C_{j}}{\partial x^{2}}
$$

The numerical model used to solve equation (3) was based on a finite difference (F-D) method, with the differential terms being replaced by F-D approximations derived from Taylor series expansions [e.g. 6]. The F-D method requires the use of a nodal grid across the regions of the material over which the diffusion processes occur. For each node, the unknown values are calculated, replacing the differential equations by difference equations. In such a system, the solution is derived for small concentration differences $(\Delta C)$, at finite locations identified by a grid-spacing $(\Delta X)$ and time intervals $(\Delta t)$. The concentration profile at a time $t$ is found by solving the F-D equations for small time increments $(\Delta t)$ iteratively. These iterations are applied until the increments sum to the desired total annealing time $t$.

The F-D equivalent to Ficks second law can be given by either an explicit or implicit representation. The explicit F-D method enables the determination of an unknown concentration value at one node to be expressed directly in terms of concentration values at the previous time step. This method is commonly used when there is a strong time dependent boundary condition, and requires the use of fairly small time increments. According to the explicit scheme, the first and second derivative of the concentration gradients are represented by central difference formulae as:

$$
\begin{gathered}
\frac{\partial C_{i}}{\partial x}=\frac{C_{J, N+1}^{i}-C_{J, N-1}^{i}}{2 \Delta X} \\
\frac{\partial^{2} C_{i}}{\partial x^{2}}=\frac{C_{J, N+1}^{i}-2 C_{J, N}^{i}+C_{J, N-1}^{i}}{\Delta X^{2}}
\end{gathered}
$$

where $i$ refers to the diffusing element, $N$ is the node number and the suberscript $J$ is the current iteration at time $t$. These equations apply to all nodes $n$, where the adjacent 
nodes $n-1$ and $n+1$ exist. A forward difference, expression was used for the time derivative in the left hand side of equation (3),

$$
\frac{\partial C_{i}}{\partial t}=\frac{C_{J+1, N}^{i}-C_{J, N}^{i}}{\Delta t}
$$

where $J+1$ is the next iteration at time $t+\Delta t$. The first derivative of the diffusion coefficients in (3) are also represented by a central difference formula:

$$
\frac{\partial \tilde{D}_{i j}^{n}}{\partial x}=\frac{\tilde{D}_{i j(J, N+1)}^{n}-\tilde{D}_{i j(J, N-1)}^{n}}{2 \Delta X}
$$

Substitution of equations (5)-(8) in (3), would provide a formula for the unknown concentrations at $J+1$ time step $C_{J+1, N}^{i}$ in terms of known concentrations, diffusion coefficients and boundary conditions at step $J$, explicitly. Such an explicit scheme has the advantage of being able to account for variable diffusion coefficients. However, the explicit F-D method can suffer from instabilities and therefore the size of the time increment $\Delta t$ must be restricted by a stability criterion, typically given as:

$$
\Delta t \leq 0.25 \frac{\Delta X^{2}}{\tilde{D}_{i j}^{n}}
$$

where $\Delta X$ is the grid spacing. A consequence of this stability criterion is that there are limitations on having comparatively large diffusion coefficients within the system.

The implicit F-D method proposed by Crank and Nicolson [7] requires the solution of a set of $N$ simultaneous equations at each time step; the number of unknown values is related to the number of nodes within a grid. Therefore, this method involves a significantly greater amount of computational work at each time step when compared to the explicit method. However, the advantage is that this method is stable for all values of $\Delta X^{2} / \tilde{D}_{i j}^{n}$ in equation (9). The implicit solution is derived by replacing the second derivative of equation (4) by the average of its F-D representations on the $(J+1)$ and $J$ th iterations as

$$
\frac{\partial^{2} C_{i}}{\partial x^{2}}=\frac{1}{2}\left\{\frac{C_{J+1, N+1}^{i}-2 C_{J+1, N}^{i}+C_{J+1, N-1}^{i}}{\Delta X^{2}}+\frac{C_{J, N+1}^{i}-2 C_{J, N}^{i}+C_{J, N-1}^{i}}{\Delta X^{2}}\right\}
$$

Substitution of equations (7) and (10) in (4) produces a system of linear equations which, after applying appropriate boundary conditions, can be solved efficiently for $C_{J, N}^{i}$ by a tridiagonal matrix algorithm [8]. 
In this work, therefore, we used the explicit scheme described above for all elements except for rapidly diffusing carbon, for which the Crank and Nicolson implicit F-D method was used; see Section 3.4.

\subsection{Oxidation model}

There have only been a few studies into the oxidation kinetics of bond coat materials, and in the absence of a model and data specific for the coating being investigated, the model proposed by Meier et al. for a Ni-Co-Cr based bond coat was used [9]. The model assumes that only $\mathrm{Al}$ is oxidised at the coating surface. The diffusion of elements within the oxide are not considered in the current model. For isothermal oxidation, the boundary condition at the oxide/coating interface is given as the rate of $\mathrm{Al}$ consumption, where the thickness $\delta$ of the oxide scale in $\mu \mathrm{m}$ is given by

$$
\delta=\left[\exp \left\{Q\left(\frac{1}{T_{0}}-\frac{1}{T}\right)\right\} t\right]^{n}
$$

where $Q$ is a constant and equal to $27777.4, T$ is the temperature in Kelvin, $T_{0}$ is $2423.7 \mathrm{~K}, t$ is time in seconds and $n$ is equal to 0.332 . For the rate of change of oxide thickness, the first derivative of equation (11) was taken with respect to time:

$$
\dot{\delta}=n\left[\exp \left\{Q\left(\frac{1}{T_{0}}-\frac{1}{T}\right)\right\}\right]^{n} t^{n-1}
$$

Following a similar approach proposed by Nesbitt et al. [1] and Lee et al.[10] the rate of change of oxide scale thickness in equation (12) can be used to calculate the $\mathrm{Al}$ atomic flux in the coating, which was used as a boundary condition in the diffusion model. The Al flux away from the oxide/coating interface into the oxide can be determined by the following equation:

$$
\left.J_{\mathrm{Al}}\right|_{x=\psi^{-}}=\dot{\delta} \rho_{o x} r
$$

where $\psi$ represents the position of the interface, $\dot{\delta}$ is the rate at which the oxide grows, $\rho_{o x}$ is the density of the oxide and $r$ is the ratio of atomic weight of $\mathrm{Al}$ to oxygen in $\mathrm{Al}_{2} \mathrm{O}_{3}$. This flux of $\mathrm{Al}$ is equal to the diffusional flux of $\mathrm{Al}$ in the coating towards the interface. However, as the interface between the oxide and the coating is moving, the flux away from the interface into the oxide is related to the flux towards the interface by the following equation:

$$
\left.J_{\mathrm{OX}}\right|_{x=\psi^{-}}=\left.\alpha J_{i}\right|_{x=\psi^{+}}
$$

where $\psi^{-}$and $\psi^{+}$refer to the oxide and metal sides of the oxide/coating interface, respectively, with $\alpha$ given by: 


$$
\alpha=\frac{1}{1-V_{\mathrm{Al}} C_{J, 0}^{\mathrm{Al}}}
$$

where $V_{\mathrm{Al}}$ is the partial molar volume of $\mathrm{Al}$, taken as $7.1 \times 10^{6} \mathrm{~m}^{3} / \mathrm{mol}[11]$, and $C_{J, 0}^{\mathrm{Al}}$ is the concentration of $\mathrm{Al}$ at iteration $J$ at the oxide/coating interface.

It should, however, be noted that the oxidation model given in equation (11) was developed for temperatures above the temperature range used in the current modelling work and hence the parameters in equation (11) had to be extrapolated to lower temperatures.

The Al flux towards the coating surface can also be represented by:

$$
\left.J_{i}\right|_{x=\psi^{+}}=-\sum_{j=1}^{n-1} \tilde{D}_{i j}^{n} \frac{\partial C_{j}}{\partial x}
$$

for which the concentration gradients at the interface have to be determined using second order forward difference equations as follows:

$$
\left.\frac{\partial C_{j}}{\partial x}\right|_{x=\psi}=\frac{-C_{j, 2}^{i}+4 C_{j, 1}^{i}-3 C_{j, 0}^{i}}{2 \Delta X}
$$

equation (17) is then used in conjunction with equations (12)-(16) to calculate the concentrations at the oxidation boundary.

\subsection{Thermodynamic model}

The thermodynamic equilibrium calculations were performed using the Application Interface [12] of MTDATA [13]. The MTDATA program consists of a numerical technique for the minimisation of Gibbs energy, and was used in conjunction with a thermodynamic database for Ni-based superalloys, Ni-DATA [14]. The code calls the MTDATA application interface at each time-step, with the concentration at each node in the diffusion grid sequentially. It should be noted that the system temperature and pressure are assumed to remain constant during each simulations, with the pressure set to be one atmosphere and the temperature chosen as the isothermal ageing temperature. The thermodynamic calculations in turn return a description of equilibrium phases which are likely to be present at each node. This description includes the fractional phase composition and the composition within each of the phases. These data are used by the diffusion code to calculate an effective diffusion coefficient for each element at each node.

It should be noted that diffusion within these systems is a non-equilibrium process; however the results provided by thermodynamic calculations are obtained under the 
hypothesis that thermodynamic equilibrium conditions exist at a given temperature and concentration locally. Although non equilibrium conditions exist in reality, the thermodynamic calculations provide a good indication of the phases present as a function of time, temperature and composition.

Each thermodynamic calculation is computationally expensive because of the inclusion of a large number of elements and alloy phases. Furthermore, there is a requirement to perform a large number of such calculations due to the need to solve at each spatial grid point at every time step. Therefore, to address these problems, the simulations have been performed in parallel so as to minimise the computational run time. This has been achieved by partitioning the spatial grid points between the processors, which is possible because the thermodynamic calculations at each spatial grid point are independent.

\section{Implementation}

\subsection{Zonal division}

In the initial stages of the simulation, the diffusion was modelled only at two separate locations in the coating/substrate system, as independent phenomena. These are designated as Zone 1 and Zone 2, where concentration gradients are steepest; Zone 1 is at the surface of the coating, near the oxide/coating interface and related to the diffusional transport due to oxidation. Zone 2 covers the coating/substrate interface which is related to the interdiffusion between the two materials. Regions outside these zones were assumed to have zero concentration gradients and hence no interdiffusion fluxes should exist in these regions. Considering interdiffusion at the two zones as independent problems allowed computational resources to be concentrated more efficiently.

The oxidation of the coating (Zone 1) can be treated as the oxidation of a semi-infinite material which only affects the immediate area underneath the surface of the coating. In a similar manner, coating/substrate interdiffusion (Zone 2) can be treated as a case of interdiffusion between two semi-infinite materials, the coating and substrate.

At all temperatures, each zone was assigned 40 nodes and the starting node spacing at 850,950 and $1050{ }^{\circ} \mathrm{C}$ were $0.2,0.5$ and $1.2 \mu \mathrm{m}$ respectively. The initial coating thicknesses used at these temperatures were 350,215 and $350 \mu \mathrm{m}$ respectively. The initial coating thickness was determined by experimental measurements and an appropriate grid spacing chosen.

\subsection{Initial concentration distribution}

An error function solution was used to initially assign the coating and substrate compositions to the nodes in order to provide a smooth transition between the coating and 
substrate compositions. The initial concentrations of the nodes in Zone 2 were given by:

$$
C_{j}=C_{j}^{\mathrm{C}}+\left[\frac{C_{j}^{\mathrm{S}}-C_{j}^{\mathrm{C}}}{2}\left(1+\operatorname{erf}\left\{k \frac{\left(x-x_{T}\right)}{x_{\mathrm{Z} 2}}\right\}\right)\right]
$$

where $C_{j}^{\mathrm{C}}$ and $C_{j}^{\mathrm{S}}$ are the initial concentrations of element $j$ in the coating and substrate respectively, $x_{T}$ is the thickness of the coating and $x_{\mathrm{Z} 2}$ is the length of zone 2 . The constant $k$ determines the sharpness of the distribution variation; for this work $k=0.33$ was used.

The compositions of the coating and substrate used in these simulations are given in Table 1. The presence of $Y$ was neglected in the model as it is not allowed for within the thermodynamic database, and because of its small concentration in the coating. However, $\mathrm{Y}$ is generally thought to form oxides within such coatings and does not take part in the formation of any of the main coating phases; therefore, the predictions of the phases within the bulk of the coating are likely to be a reasonable representation. It is at the same time recognised that $\mathrm{Y}$ may have a significant impact on the oxidation rate, which will be addressed in future research.

\begin{tabular}{lcc}
\hline & & Composition (wt.\%) \\
& Bond-coat & Substrate \\
\hline $\mathrm{Al}$ & 8.5 & 5.6 \\
$\mathrm{Co}$ & 23.0 & 9.6 \\
$\mathrm{Cr}$ & 15.0 & 6.4 \\
$\mathrm{Mo}$ & 0.0 & 0.6 \\
$\mathrm{Ta}$ & 7.0 & 6.5 \\
$\mathrm{Ti}$ & 0.0 & 1.0 \\
$\mathrm{Re}$ & 0.0 & 3.0 \\
$\mathrm{~W}$ & 0.0 & 6.4 \\
$\mathrm{C}$ & 0.0004 & 0.0024 \\
\hline
\end{tabular}

Table 1: Bond-coat and substrate compositions used in the current study.

\subsection{Zone expansion and merger}

The simulation process was based on a flexible grid scheme. As such, the diffusion zones expand or contract with time to match the position of the moving zone and phase boundaries. As the simulation progressed, the calculated concentration profiles extend further into the coating, in case of Zone 1, and both into the substrate and coating in the case of Zone 2. As a result the boundaries of the zones were extended accordingly while maintaining the semi-infinite boundary conditions that exist at the 
edges of the zones. The difference in concentration $\left(\left|d C_{i}\right|\right)$ of an element between the two outermost nodes of a zone was taken as the criterion for expansion. If $\left|d C_{i}\right|<0.0005$ at.\%, the zone was extended by a distance equivalent to the current node spacing, in the relevant direction. The expansion process involved relocation of the nodes and interpolating the concentrations onto the new grid locations using a spline-interpolation process, similar to the scheme outlined in [1]. The expansion process continued until the diffusion fields of the two zones overlapped (soft impingement) and from that stage, the diffusion zones were combined together to form a single zone. The merging process involved the relocation of the nodes in Zones 1 and 2 into a single zone (Zone 1) so that they formed a continuous, equi-spaced zone.

\subsubsection{Treatment of moving boundaries}

The interface between the oxide-scale and coating represents a moving phase boundary, which moves at a rate given by:

$$
\frac{d \psi}{d t}=-V_{i} J_{\mathrm{OX}}
$$

and as such was treated numerically according to the grid-point motion technique suggested by Murray and Landis [15]. The main features of this method are that (i) the number of grid points is kept constant, and (ii) the moving phase boundary is always located on a node. This makes the grid either shrink or expand at each time step, depending on the direction of the expansion. It also requires redistribution of grid points at each time step. Application of this method to Zone 1, which is the zone affected by the moving oxidation/bond coat phase boundary, results in the grid spacing in the zone being reduced by a distance $\Delta \psi /\left(N_{\mathrm{Z} 1}-1\right)$, where $\Delta \psi$ is the finite distance the oxidation interface moves during a time step, calculated by integrating equation (19), and $N_{\mathrm{Z} 1}$ is the number of nodes in Zone 1. As a result of the relocation of nodes in the zone, the concentration of each element $i$ at each node $N$ of the zone has to be incremented at each time-step $J$ by a factor given by

$$
\Delta C_{J, N}^{i}=\frac{d \psi}{d t} \frac{\left(N_{\mathrm{Z} 1}-N\right)}{\left(N_{\mathrm{Z} 1}-1\right)} \frac{\left(C_{J, N+1}^{i}-C_{J, N-1}^{i}\right)}{2 \Delta X_{\mathrm{Z} 1}}
$$

where $\Delta X_{\mathrm{Z} 1}$ is the grid spacing of Zone 1 .

\subsection{Carbon diffusion}

Although $\mathrm{C}$ is not a deliberate addition in either the coating or substrate composition, there was evidence that carbide phases precipitate after long term aging of the experimental samples. In order to explore the possibility of predicting these phases, $\mathrm{C}$ was 
therefore incorporated in the model. However, in the case of $\mathrm{C}$, the diffusion coefficient is several orders of magnitude larger than those of the rest of the elements. The large diffusion coefficient severely limits the size of time step that can be used in an explicit solution scheme according to equation (9) and therefore results in extremely long computation times. Consequently the diffusion of $\mathrm{C}$ was treated using the Crank-Nicolson implicit scheme, outlined in Section 2.1. A parallel, equi-spaced grid was implemented for $\mathrm{C}$ diffusion, independent of the two zone grid used for the other elements. At each time step, the $\mathrm{C}$ diffusion profile was interpolated onto the main grid to allow phase equilibrium calculations to be performed at the main nodes with $\mathrm{C}$ concentrations incorporated.

\subsection{Diffusion coefficients}

The diffusion model used is based on the binary interdiffusion coefficient of each element with Ni. The cross interdiffusion coefficients are only available for a few ternary systems which are for limited concentration and temperature fields. However, these are generally up to an order of magnitude smaller than the major coefficients, and were therefore ignored in this work. Where reliable concentration dependent binary data were available, they were incorporated into the model in terms of activation energies and frequency factors as polynomial functions of concentration.

\subsubsection{Diffusion in the $\gamma$ phase}

The interdiffusion coefficient $\tilde{D}$ obeys the Arrhenius relationship as follows:

$$
\tilde{D}=\tilde{D}_{0} \exp \{-Q / \mathrm{RT}\}
$$

where $Q, \tilde{D}_{0}, \mathrm{R}$ and $T$ are the activation energy, frequency factor, universal gas constant and absolute temperature respectively.

When such data were available, the concentration dependence of the elements in the $\gamma$ phase was modelled by fitting a third degree polynomial, derived from the Arrhenius relationship, to the $\ln \tilde{D}_{0}$ and $Q$ terms:

$$
\tilde{D}=\exp \left\{\ln \tilde{D}_{0}-\frac{\ln Q}{R T}\right\}
$$

The polynomial parameters representing $\ln \tilde{D}_{0}$ and $Q$ are given in Table 2, together with the source from which they were obtained; the polynomial parameters correspond to the following expressions: 


$$
\begin{aligned}
Q & =A_{Q}+B_{Q} C_{i}+C_{Q} C_{i}^{2}+D_{Q} C_{i}^{3} \\
\ln D_{0} & =A_{D 0}+B_{D 0} C_{i}+C_{D 0} C_{i}^{2}+D_{D 0} C_{i}^{3}
\end{aligned}
$$

where $C_{i}$ represents the concentration of element $i$ in atomic fractions. It should be noted that for $\mathrm{Al}, \mathrm{C}$ and $\mathrm{Cr}$, reliable concentration dependent diffusion data do not exist for the temperature range considered in the simulations and therefore, concentration independent diffusion coefficients were used in these cases.

\begin{tabular}{cccccc}
\hline & \multicolumn{5}{c}{$Q=A_{Q}+B_{Q} C+C_{Q} C^{2}+D_{Q} C^{3}$} \\
Element & $A_{Q}$ & $B_{Q}$ & $C_{Q}$ & $D_{Q}$ & Reference \\
\hline $\mathrm{Al}$ & 267872.00 & 0.0 & 0.0 & 0.0 & {$[16]$} \\
$\mathrm{C}$ & 138164.40 & 0.0 & 0.0 & 0.0 & {$[17]$} \\
$\mathrm{Co}$ & 277341.76 & 66459.557 & -161296.20 & 103145.10 & {$[18]$} \\
$\mathrm{Cr}$ & 256990.00 & 0.0 & 0.0 & 0.0 & {$[19]$} \\
$\mathrm{Mo}$ & 267943.98 & 401832.57 & 84552.276 & 3083.533129 & {$[20]$} \\
$\mathrm{Ta}$ & 245665.10 & 386576.60 & 82003.439 & 2842.274527 & {$[21]$} \\
$\mathrm{Ti}$ & 235752.04 & 431062.85 & -5619895.9 & -15667534.3 & {$[22]$} \\
$\mathrm{Re}$ & 259018.77 & -518079.88 & 2606.3586 & -251.9939130 & {$[21]$} \\
$\mathrm{W}$ & 286096.55 & -1486255.9 & -2030.5180 & -11.82006453 & {$[21]$} \\
\hline \multicolumn{5}{c}{$\ln D_{0}=A_{D 0}+B_{D 0} C+C_{D 0} C^{2}+D_{D 0} C^{3}$} & $C_{\text {Max }}$ \\
\hline Element & $A_{D 0}$ & $B_{D 0}$ & $C_{D 0}$ & $D_{D 0}$ & $($ At. fraction) \\
\hline $\mathrm{Al}$ & -8.5844019 & 0.0 & 0.0 & 0.0 & \\
$\mathrm{C}$ & -11.512926 & 0.0 & 0.0 & 0.0 & - \\
$\mathrm{Co}$ & -8.3511690 & -0.62406121 & -0.99282309 & -0.027067801 & 0.900 \\
$\mathrm{Cr}$ & -9.7145214 & 0.0 & 0.0 & 0.0 & - \\
$\mathrm{Mo}$ & -10.325493 & 41.560840 & -112.43721 & 366.25500 & 0.064 \\
$\mathrm{Ta}$ & -11.356740 & 57.955144 & -1432.0071 & 9964.6323 & 0.035 \\
$\mathrm{Ti}$ & -11.326019 & 47.902887 & -612.70667 & 34.973423 & 0.060 \\
$\mathrm{Re}$ & -14.078119 & 1.9533470 & -2057.9530 & 26267.299 & 0.034 \\
$\mathrm{~W}$ & -10.495898 & -81.674914 & -1554.5447 & 14552.435 & 0.034 \\
& & \multicolumn{5}{c}{} &
\end{tabular}

Table 2: Polynomial coefficients used to model $\ln \tilde{D}\left(\mathrm{~m}^{2} / \mathrm{s}\right)$ in equation (22) for concentration $C$ of each element given in atomic fraction. The parameters are valid only up to the maximum concentration $C_{\mathrm{Max}}^{i}$. For concentrations above $C_{\mathrm{Max}}^{i}$, the $\tilde{D}$ at $C_{\mathrm{Max}}^{i}$ was used. 


\subsubsection{Diffusion in the $\gamma^{\prime}$ phase}

For $\mathrm{Al}$ diffusion in the $\gamma^{\prime}$ phase, the diffusion coefficients were determined by fitting a second degree polynomial to Arrhenius parameters provided by Ikeda et al. [23]. The polynomial expressions for the frequency factor $\tilde{D}_{0}$ in $\mathrm{m}^{2} / \mathrm{s}$ and activation energy $Q$ in $\mathrm{kJ} / \mathrm{mol}$ are given by the following expressions [23]:

$$
\begin{aligned}
\log _{10} \tilde{D}_{0} & =-1000 C^{2}+530 C-67.4 \\
Q & =5000 C^{2}-3750 C+930
\end{aligned}
$$

The concentration independent Arrhenius parameters $\left(Q\right.$ and $\left.D_{0}\right)$ for Co and Cr were taken from data by Minamino et al. [24], whereas for Ti, data published by St. Frank et al. were used [25]. The values for the parameters used for $\mathrm{Co}, \mathrm{Cr}$ and $\mathrm{Ti}$ are presented in Table 3.

\begin{tabular}{ccc}
\hline & $\begin{array}{c}\text { Activation energy } \\
\text { Element }\end{array}(\mathrm{kJ} / \mathrm{mol})$ & $\begin{array}{c}\text { Frequency factor } \\
\tilde{D}_{0}\left(\mathrm{~m}^{2} / \mathrm{s}\right)\end{array}$ \\
\hline $\mathrm{Co}$ & 325.0 & $4.2 \times 10^{-3}$ \\
$\mathrm{Cr}$ & 366.0 & $1.10 \times 10^{-1}$ \\
$\mathrm{Ti}$ & 424.6 & $8.59 \times 10^{-1}$ \\
\hline
\end{tabular}

Table 3: Arrhenius parameters (activation energy $Q$ and frequency factor $\tilde{D}_{0}$ ) of $\tilde{D}$ for a number of diffusing elements in the $\gamma^{\prime}$ phase.

\subsubsection{Diffusion in the $\beta$ phase}

In the case of the $\beta$ phase, reliable data exist only for Al. The concentration dependence of Arrhenius parameters for $C_{A l}>0.48$ at.\% were therefore modelled by fitting a third order polynomial to the data reported by Wei et al. [26] and these are given by the following pair of equations:

$$
\begin{aligned}
& \ln \tilde{D}_{0}=248416 C^{3}-380687 C^{2}+194221 C-32999.7 \\
& Q=\left(2.63889 C^{3}-4.04333 C^{2}+2.06112 C-0.349333\right) \times 10^{9}
\end{aligned}
$$

However, for Al concentrations $C<0.48$ at.\%, data published by Nakamura et al. [27] were applied with the following expressions derived by polynomial regression: 


$$
\begin{aligned}
& \ln D_{0}=-7890.25 C^{3}+10962.7 C^{2}-5032.65 C+759.432 \\
& Q=\left(-1.51515 C^{3}+2.02987 C^{2}-8.96807 C-0.13397\right) \times 10^{8}
\end{aligned}
$$

\subsubsection{Diffusion in TCP and Carbide phases}

There is an absence of diffusion data for elements within TCP and carbide phases. However, being highly ordered phases, diffusion in these phases are expected to be much slower than in the disordered $\gamma$-fcc phase. Therefore, the interdiffusion coefficient of an element in these phases was assumed to be a fraction $f_{D}$ (in this case $f_{D}=0.05$ ) of the same element in the $\gamma$ phase represented as:

$$
\tilde{D}_{i, \text { Carbides } / \mathrm{TCP}}=f_{D} \tilde{D}_{i, \mathrm{fcc}}
$$

Although the value chosen for $f_{D}$ was estimated in line with expectation of the relatively slow diffusion in these complex phases, this value only has a small influence on the computed effective diffusion coefficient (see Section 3.5.5), because the amounts in which these phases were present in the system were very small.

\subsubsection{Effective diffusion coefficient}

When calculating an effective diffusion coefficient for an element, not only the diffusion coefficient through each phase present but also their morphologies should be taken into account. Previous studies $[2,28]$ have simplified the multiphase system as a mixture of a diffusing matrix and non-diffusing precipitate phases. The precipitate phases were considered to be spherical in shape, and their effect was to 'block' the diffusion paths in the matrix phase. The effective resistance offered by these particles was introduced by means of a 'labyrinth factor', which is a function of the volume fraction of the precipitate phases. In this work, however, the diffusion of elements in precipitate phases has been taken into account, and the phase morphologies seen in experiments are too diverse to be approximated by a system of spheres. Hence, the above approach is not directly applicable and in the absence of a model which can fully incorporate diverse precipitate morphologies in which diffusion can occur, the following simpler model was used. At each node in the grid, an effective diffusion coefficient $\tilde{D}_{i}^{\text {Eff }}$ for each element $i$ was calculated by weighting in the volume fraction of each phase $P$ at that node, and the interdiffusion coefficient of that element in each phase $\tilde{D}_{i, P}$ according to equation (32)

$$
\tilde{D}_{i}^{\mathrm{Eff}}=\sum_{P} f_{P}^{V} \tilde{D}_{i, P}
$$


The volume fractions of each phase were determined from the mass fractions $f_{P}^{M}$ obtained from thermodynamic calculations using the following equation:

$$
f_{P}^{V}=\frac{f_{P}^{M} / \rho_{P}}{\sum_{P}\left(f_{P}^{M} / \rho_{P}\right)}
$$

where $\rho_{P}$ is the density of phase $P$. The values used for the density of the $\gamma, \gamma^{\prime}, \beta$ and TCP/carbide phases are presented in Table 4. In this work the contribution of grain-boundary diffusion to the effective diffusion coefficient was ignored.

\begin{tabular}{ccc}
\hline Phase & Density $\left(\mathrm{kg} / \mathrm{m}^{3}\right)$ & Reference \\
\hline$\gamma$ & 8908 & {$[29]$} \\
$\gamma^{\prime}$ & 7230 & {$[30]$} \\
$\beta$ & 5900 & {$[31]$} \\
TCPs/Carbides & 7140 & \\
\hline
\end{tabular}

Table 4: Density values of the $\gamma, \gamma^{\prime}, \beta$ and TCP/Carbide phases used in the model.

\section{Experimental Procedure}

An MCrAlY coating was applied to a CMSX4 substrate (see Table 1) in the form of cylindrical bars of $\sim 13 \mathrm{~mm}$ in diameter by a commercial low pressure air plasma spray process, and followed by a standard coating diffusion heat treatment. The coated samples were then isothermally exposed in a laboratory furnace air environment for up to $10000 \mathrm{~h}$ at temperatures between 850 and $1050{ }^{\circ} \mathrm{C}$, and subsequently air cooled. The samples were then prepared for metallographic examination by mounting in conducting Bakelite, grinding on $\mathrm{SiC}$ paper, polishing with $1 \mu \mathrm{m}$ diamond paste before final etching in a $10 \%$ phosphoric acid solution at $5 \mathrm{~V}$ DC for 5-10 s. Microstructural examination was then carried out in a Zeiss (Leo) 1530 VP FEGSEM with and EDAX Pegasus EDX system operated at $20 \mathrm{kV}$.

\section{Results and Discussion}

\subsection{Concentration Profiles}

Concentration profiles predicted by the model across the coating, interdiffusion zone and substrate were obtained at specific intervals. Figure 1 shows an example of the concentration profiles calculated from the simulations for a number of elements present 

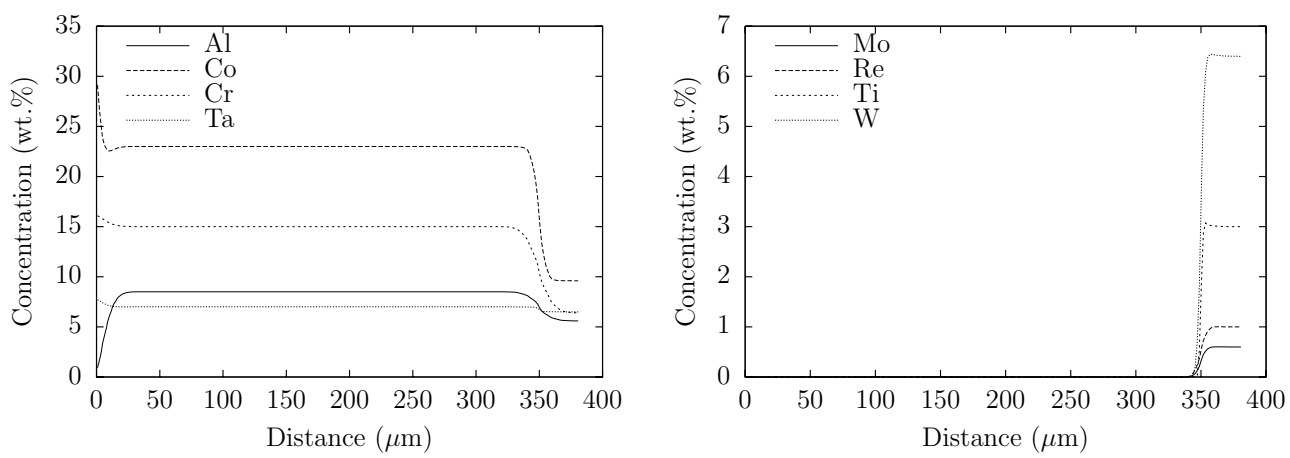

Figure 1: Predicted concentration profiles across the coating and interdiffusion zone at $850^{\circ} \mathrm{C}$ for $190 \mathrm{~h}$.

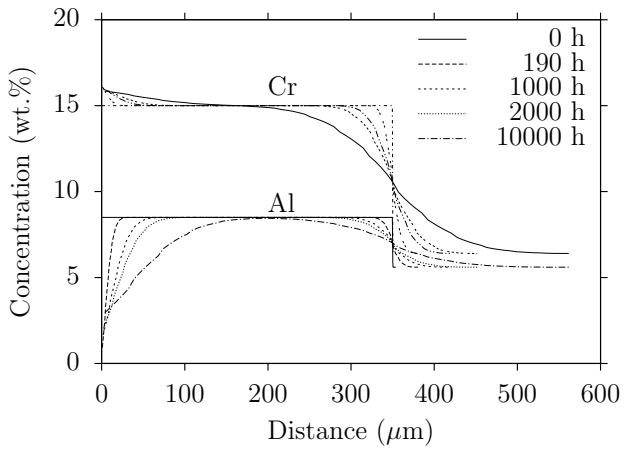

(a)

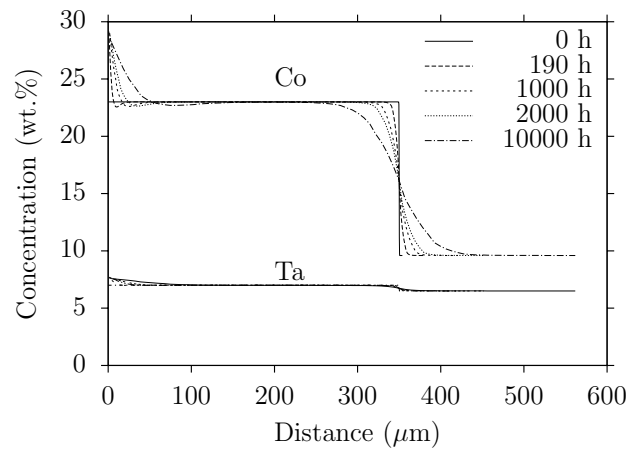

(b)

Figure 2: Simulated concentration profiles of a) $\mathrm{Al}$ and $\mathrm{Cr}$ and b) Co and $\mathrm{Ta}$ across the coating and substrate at $850^{\circ} \mathrm{C}$ after ageing at $0,190,1000,2000$ and $10000 \mathrm{~h}$.

after $190 \mathrm{~h}$ hours ageing at $850^{\circ} \mathrm{C}$. It can be seen that, in this instance, soft impingement between the two diffusion zones has not yet occurred as expected.

Figure 2 illustrates the changes in concentration profile of $\mathrm{Al}, \mathrm{Cr}$, Co and $\mathrm{Ta}$ after ageing at $850^{\circ} \mathrm{C}$ for increasing ageing times, as a direct result of both the oxidation which occurs at the coating surface and interdiffusion between the coating and substrate. The original concentration of $8.5 \mathrm{wt} . \% \mathrm{Al}$ still remains at the centre of the coating even up to $10000 \mathrm{~h}$ ageing, although on either side the concentration has been lowered by both the oxidation and coating/substrate interdiffusion. The predicted concentration profile for $\mathrm{Cr}$ at $850^{\circ} \mathrm{C}$ is affected more by the interdiffusion at the coating/substrate boundary than by the oxidation. Figure 2(b) shows the predicted composition profiles for Co and Ta across the coating and substrate at $850^{\circ} \mathrm{C}$. The Co profile illustrates similar behaviour to that of $\mathrm{Cr}$, but because its diffusion coefficient is lower, the build-up at the oxidation interface and the interdiffusion at the coating/substrate boundary occurs to a lesser degree. Although the diffusion coefficient of Ta is lower, its concentration remains approximately constant across the system because of the very small concentration difference between the substrate and the coating. 

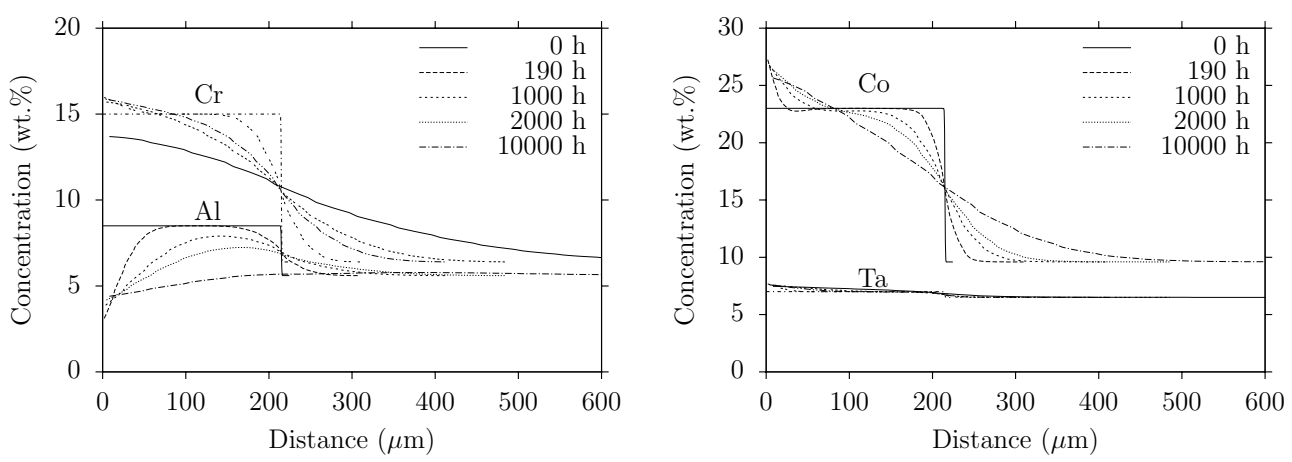

Figure 3: Simulated concentration profiles of a) $\mathrm{Al}$ and $\mathrm{Cr}$ and b) $\mathrm{Co}$ and $\mathrm{Ta}$ across the coating and substrate at $950^{\circ} \mathrm{C}$ after ageing at $0,190,1000,2000$ and $10000 \mathrm{~h}$.

Figure 3 illustrates the changes in profile of $\mathrm{Al}, \mathrm{Cr}$, Co and Ta after ageing at $950{ }^{\circ} \mathrm{C}$ with increasing exposure times. At $950^{\circ} \mathrm{C}$ the profiles appear similar to those predicted at $850^{\circ} \mathrm{C}$, although an increased amount of diffusion has occurred at the higher temperature as expected. It should be noted that the coating thickness was reduced in the $950^{\circ} \mathrm{C}$ simulations to allow for direct comparison with experimental results which indicated that the coating at $950^{\circ} \mathrm{C}$ was approximately two thirds of the thickness at $850{ }^{\circ} \mathrm{C}$.

After $10000 \mathrm{~h}$ ageing at $950{ }^{\circ} \mathrm{C}$ the $\mathrm{Al}$ was predicted to have homogenised considerably across the system, resulting in a fairly flat profile with a concentration range $4.4-5.6$ wt.\% and the concentration in the coating has fallen below that of the substrate. It is possible this increased homogenisation is a result of both increased diffusion rates at higher temperatures and the reduced thickness of the coating at $950{ }^{\circ} \mathrm{C}$ compared to that at $850^{\circ} \mathrm{C}$.

Elemental concentration profiles were constructed across the coating, interdiffusion zone and substrate using EDX in the SEM. The predicted concentration profiles are compared with those obtained from the corresponding experimental samples in Figures 4 and 5; the measured values are seen to fluctuate significantly throughout the coating, which is a direct result of the electron beam being incident on multiple phases within this area. The scatter is particularly noticeable in the interdiffusion zone. In general, there is a good agreement between the calculated and experimentally measured values of the concentration profiles across the coating and substrate.

The calculated and experimental values for $\mathrm{Al}$ and Co shown in Figure 4 follow similar profiles, therefore demonstrating good correlation between the model and the experimental data. However, at $850^{\circ} \mathrm{C}$ the simulations suggest a lower amount of $\mathrm{Al}$ was present at the coating surface after $190 \mathrm{~h}$ ageing: $\sim 0.9$ wt. $\%$ compared to the $\sim 9$ wt. $\%$ measured experimentally (although it should be noted that it is difficult to measure an exact surface concentration using EDX in the SEM due to the spot size). It is possible that the amount of $\mathrm{Al}$ consumed at the coating surface by oxidation is lower in reality than that predicted at $850{ }^{\circ} \mathrm{C}$. At $1050^{\circ} \mathrm{C}$ for $10000 \mathrm{~h}$, the simulations predict a greater 
amount of homogenisation of Co across the system than measured experimentally. In comparison, the measured values remain fairly constant throughout the coating thickness at $\sim 23 \mathrm{wt} . \%$, decreasing through the interdiffusion zone finally to the substrate concentration of $\sim 9.5 \mathrm{wt} . \%$. This difference indicates that Co is predicted to diffuse at a faster rate than is being observed experimentally. This difference could be due to the features within the interdiffusion zone, such as the presence of a $\gamma^{\prime}$ layer (discussed later in Section 5.4), reducing the interdiffusion of certain elements across the coating/substrate interface.

At the lower temperatures of 850 and $950^{\circ} \mathrm{C}$, the calculated values for the $\mathrm{Cr}$ and $\mathrm{Ta}$ concentration within the system display similar profiles to the experimentally measured data, as shown in Figures 5(a) and $5(\mathrm{~b})$. However, at $1050{ }^{\circ} \mathrm{C}$ the simulations predict a greater amount of homogenisation of these elements across the system than measured experimentally, possibly indicating that the diffusion across the $\gamma^{\prime}$ layer is not accurately modelled for these elements at the temperature.

\subsection{Phase profiles}

The starting point for the calculations was the compositions for the coating and the substrate given in Table 1, and therefore before any diffusion occurred the calculated phase distribution across the coating was uniform. Figure 6 shows that the model initially predicted the coating to consist of $\gamma, \gamma^{\prime}, \beta$ and the $\sigma$ phase, and the substrate to comprise $\gamma$ and $\gamma^{\prime}$ together with small quantities of TCP phases at $850{ }^{\circ} \mathrm{C}$. These phase predictions are in agreement with the experimental samples, except for the prediction of the $\mu$ phase for the coating and $\sigma$ phase for the substrate. The NiCoCrAlY coating in its as-received condition was experimentally found to contain $\beta$ ( NiAl), $\gamma^{\prime}\left(\mathrm{Ni}_{3} \mathrm{Al}\right)$ and $\gamma(\mathrm{Ni})$ as predicted by the simulations. However, the Cr-rich $\sigma$ phase was not observed within the samples as predicted. A relatively large amount of the $\sigma$ phase, $\sim 15.5$ wt.\%, was predicted in the coating; however, it should be noted that the TCP phases typically form after long periods of ageing as the microstructure approaches equilibrium. Nevertheless, it would appear that this value is an overestimate. Cr-rich phases were present in the interdiffusion zone, rather than in the bulk of the coating; however they were identified to be $\mathrm{M}_{23} \mathrm{C}_{6}$ carbides rather the $\sigma$ phase, indicating that the presence of carbon within the coating has altered the stability of the phases present. It has been noted [32] that there is a close relationship between $\mathrm{M}_{23} \mathrm{C}_{6}$ carbide and the $\sigma$ phase, and therefore it appears that if $\mathrm{C}$ is present in the system, it is more likely that Cr-rich carbides rather than TCP phases will be observed.

\section{$5.3 \quad \beta$ phase depletion}

The $\mathrm{Al}$ in the coating is consumed by both oxide formation at the surface and by interdiffusion at the substrate/coating interface, producing $\mathrm{Al}$ depletion zones that increase 


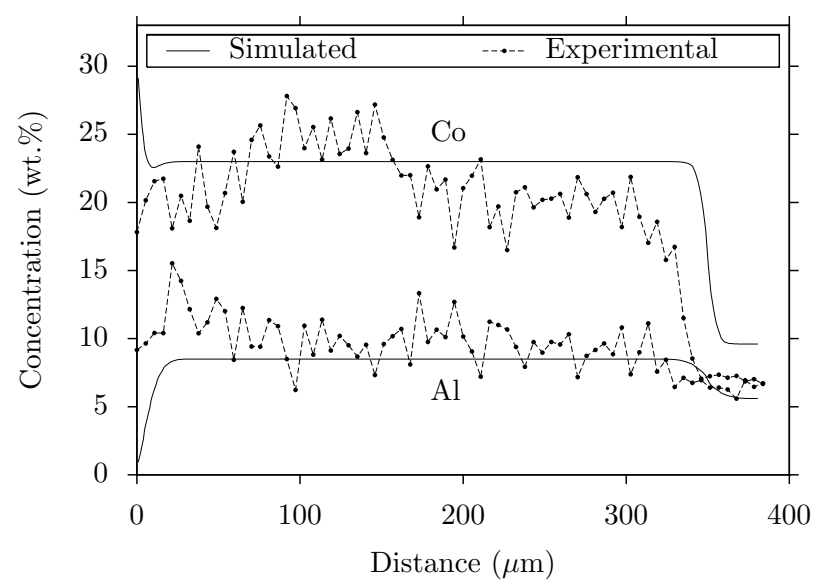

(a)

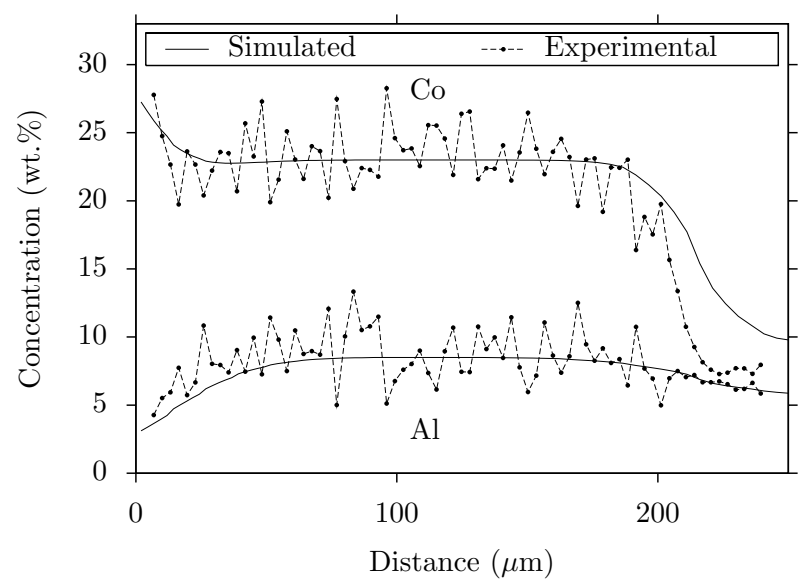

(b)

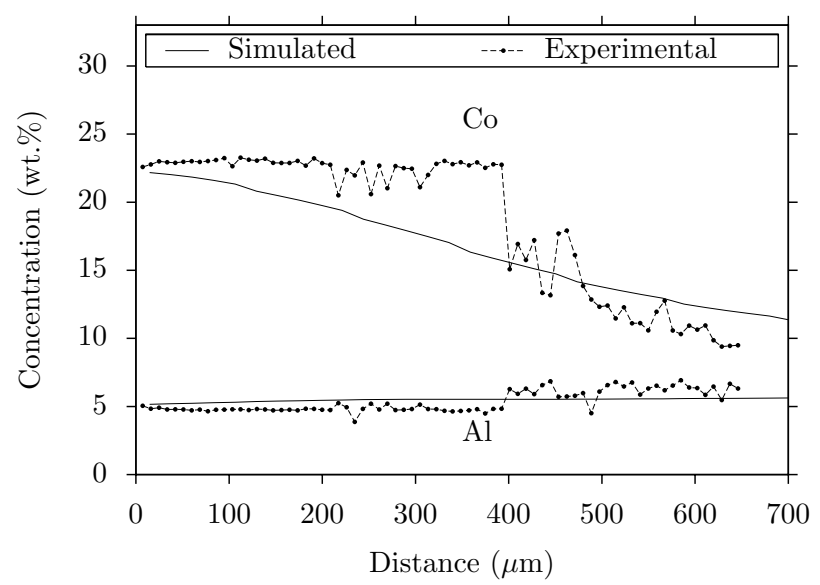

(c)

Figure 4: Comparison of the simulated (calculated) and experimentally measured concentration profiles of $\mathrm{Al}$ and Co across the coating, interdiffusion zone and substrate for (a) $190 \mathrm{~h}$ at $850^{\circ} \mathrm{C}$, (b) $190 \mathrm{~h}$ at $950^{\circ} \mathrm{C}$ and (c) $10000 \mathrm{~h}$ at $1050^{\circ} \mathrm{C}$. 


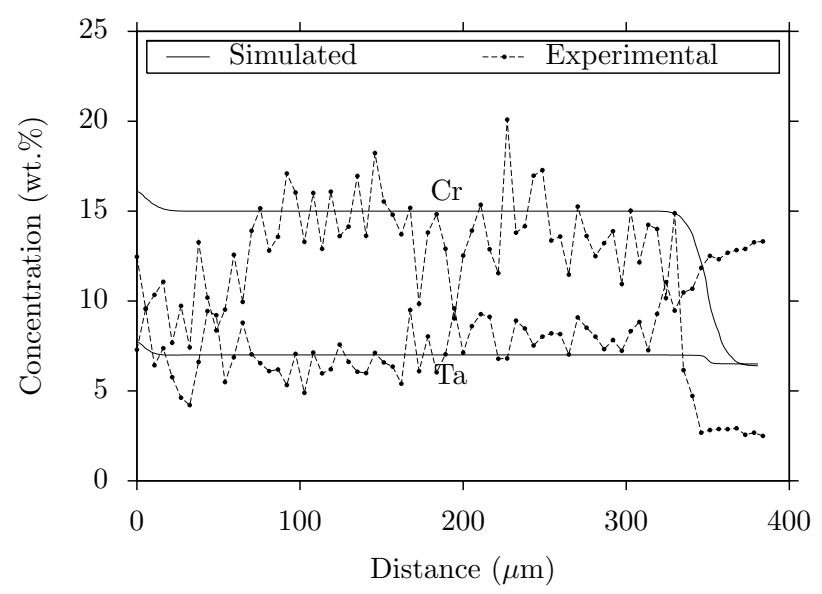

(a)

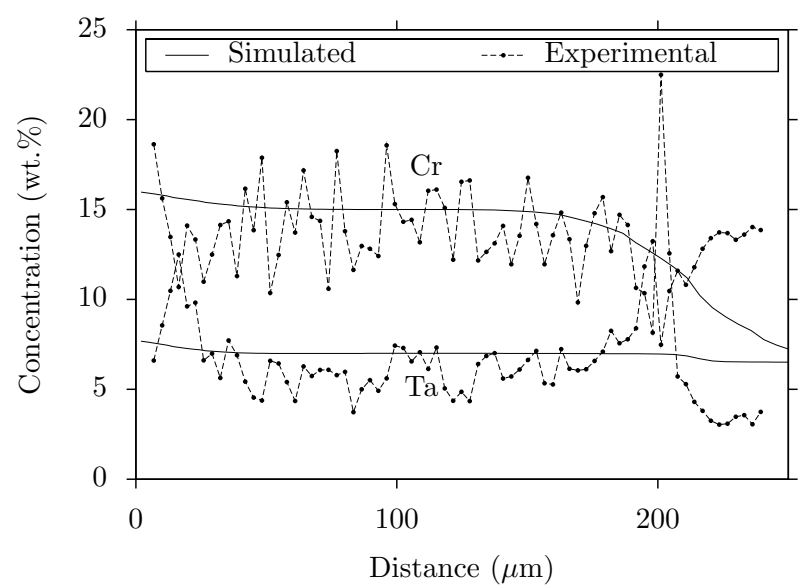

(b)

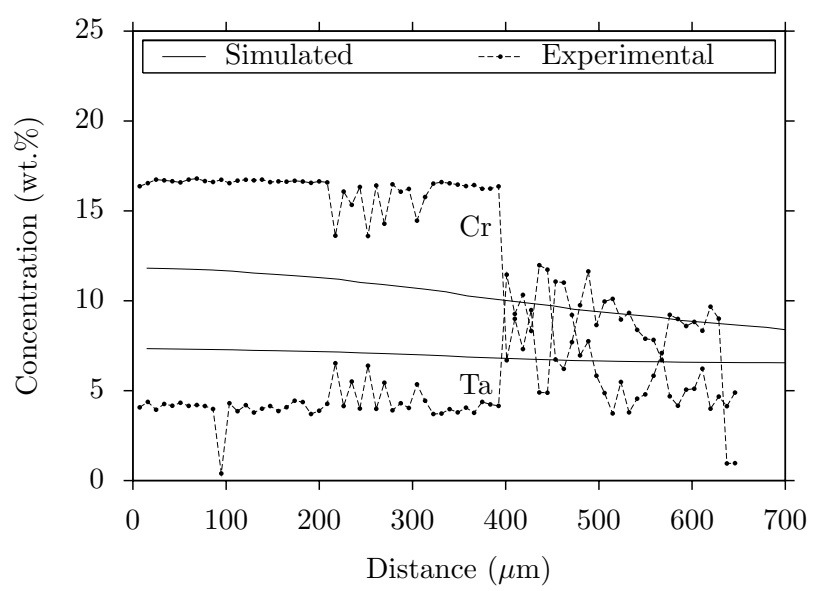

(c)

Figure 5: Comparison of the simulated (calculated) and experimentally measured concentration profiles of $\mathrm{Cr}$ and $\mathrm{Ta}$ across the coating, interdiffusion zone and substrate for (a) $190 \mathrm{~h}$ at $850^{\circ} \mathrm{C}$, (b) $190 \mathrm{~h}$ at $950^{\circ} \mathrm{C}$ and (c) $10000 \mathrm{~h}$ at $1050{ }^{\circ} \mathrm{C}$. 


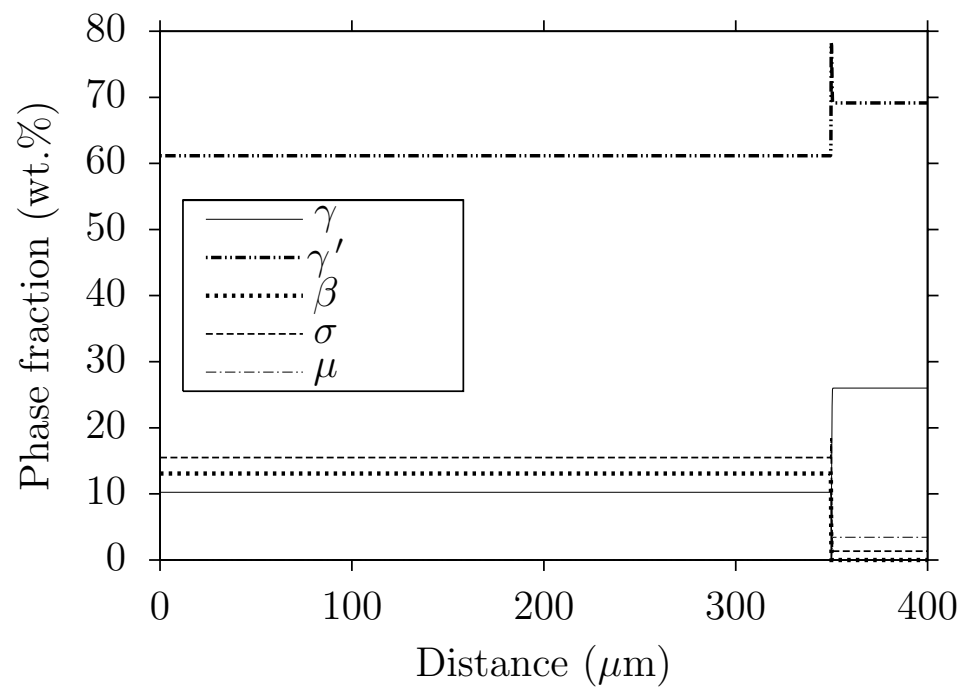

Figure 6: Predicted initial phase profiles across the coating and the substrate for the $\mathrm{NiCoCrAlY}$ coated CMSX4 at $850^{\circ} \mathrm{C}$.

in extent with time and temperature. These Al depleted zones correspond to the depletion of $\beta$-NiAl within these areas, as shown in Figure 7 . At all three temperatures, the simulation predicted that the thickness of the $\beta$ phase in the coating would reduce with increasing time as a result of the formation of $\beta$ depleted layers at both the oxidation interface and substrate sides, and also that the process is faster at higher temperatures, as illustrated in Figure 8.

After $190 \mathrm{~h}$ at $850{ }^{\circ} \mathrm{C}$, the simulation predicts the development of a $\beta$ depleted layer of $\sim 15.6 \mu \mathrm{m}$ adjacent to the coating/oxide interface. This layer increases in thickness with time, with a similar $\beta$ depleted zone developing near the coating/substrate interface, albeit at a slower rate. The same behaviour is observed in the experimental samples but at a slower rate. For example, a $\beta$ depleted surface layer of $5.2 \mu \mathrm{m}$ was observed after 190 h. A similar pattern was observed at 950 and $1050{ }^{\circ} \mathrm{C}$; see Figure 8 and 7 . A possible explanation for the reduced rate of depletion is that the amount of $\mathrm{Al}$ consumed at the coating surface by oxidation is lower in reality than the rates assumed in the simulations.

\section{$5.4 \gamma^{\prime}$ profile}

Figure 9 illustrates how the $\gamma^{\prime}$ phase is predicted to develop across the coated superalloy system at temperatures of 850,950 and $1050{ }^{\circ} \mathrm{C}$. As the exposure time increases, the fraction of the $\gamma^{\prime}$ phase adjacent to the oxide/coating interface increases as a direct result of the $\beta$ depletion. As the $\beta$ phase depletes from either side of the initial coating it is replaced by a layer of $\gamma^{\prime}$ which increases with ageing time. This production of a $\gamma^{\prime}$ layer at the coating surface was indeed observed experimentally, as shown in Figure 10. 


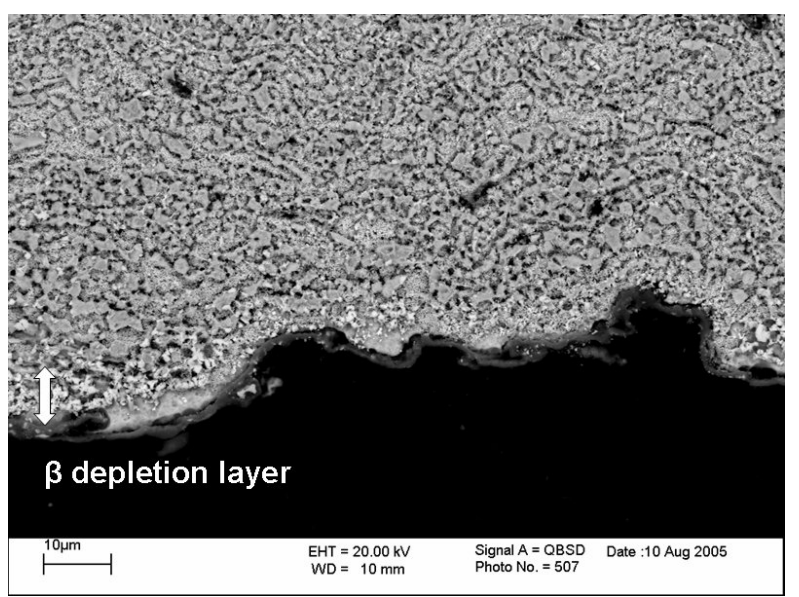

(a)

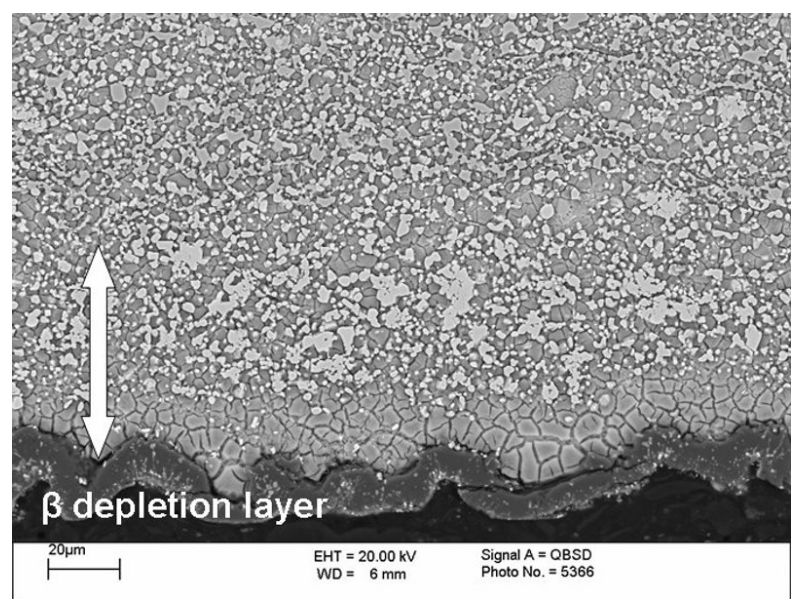

(b)

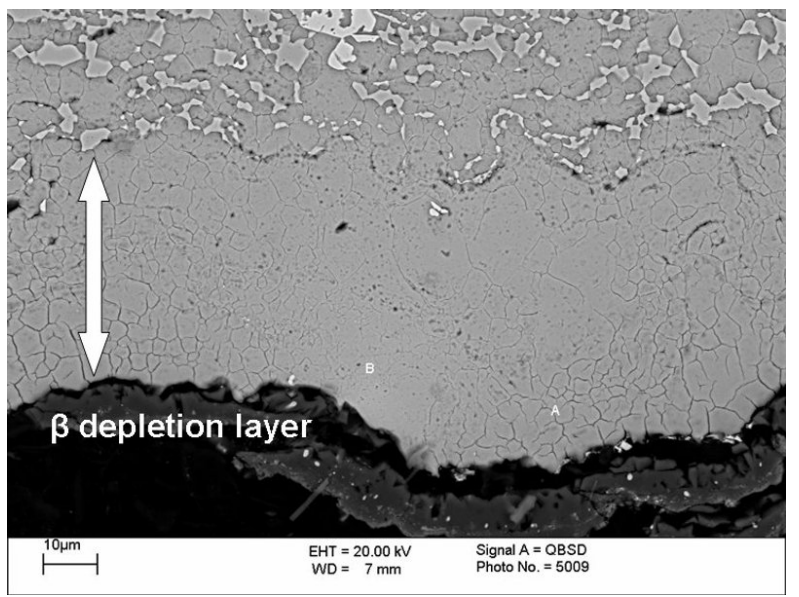

(c)

Figure 7: Scanning electron micrographs showing the depletion of the $\beta$ phase at the coating surface of the NiCoCrAlY coated CMSX4 samples thermally exposed for (a) $190 \mathrm{~h}$ at $850^{\circ} \mathrm{C}$, (b) $10000 \mathrm{~h}$ at $950^{\circ} \mathrm{C}$ and (c) $2000 \mathrm{~h}$ at $1050^{\circ} \mathrm{C}$. 


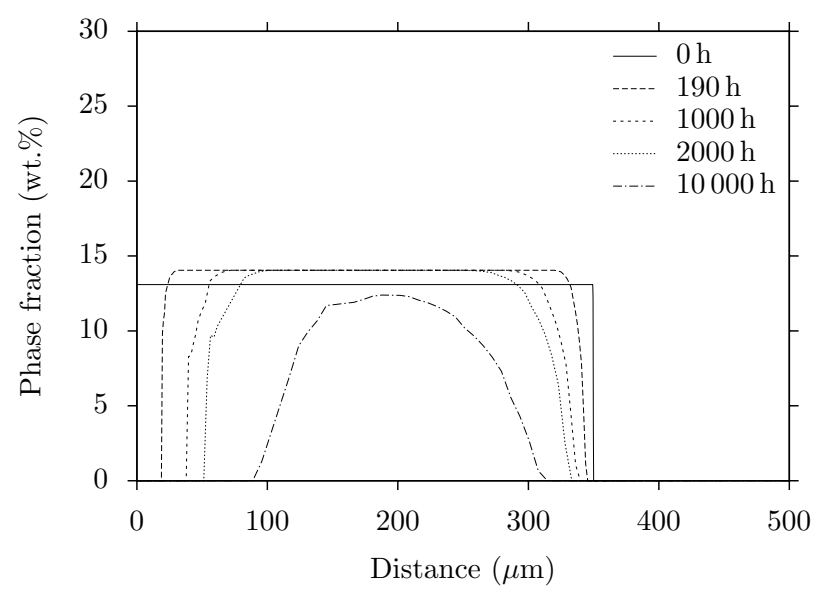

(a)

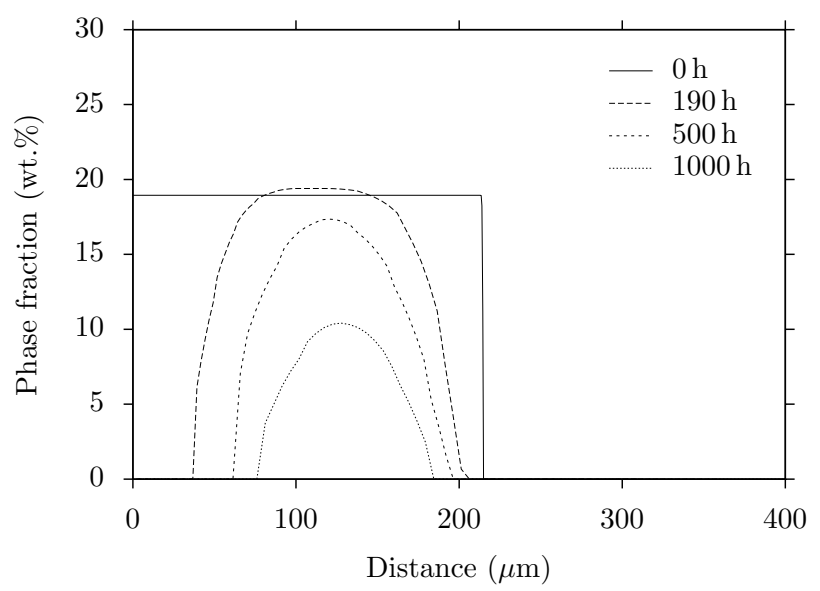

(b)

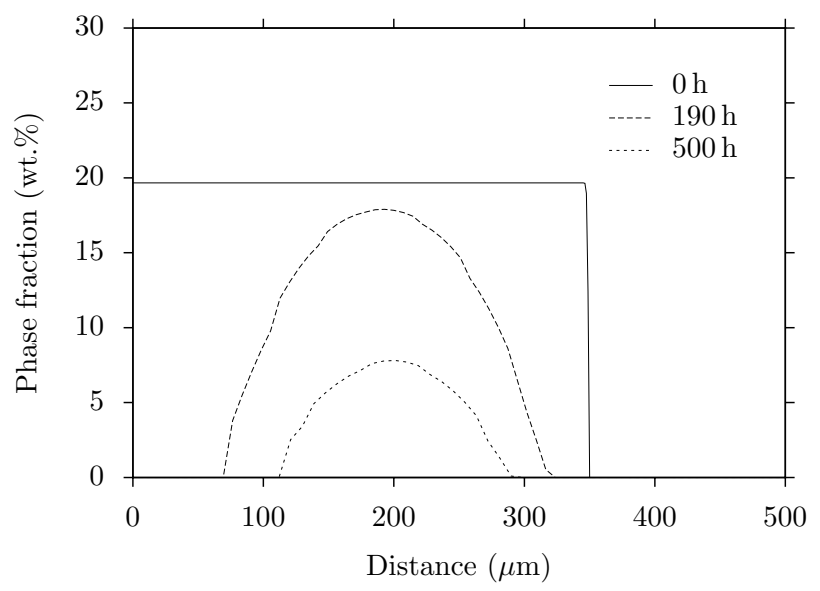

(c)

Figure 8: Simulated predictions of the $\beta$ phase profiles across the coating at (a) $850{ }^{\circ} \mathrm{C}$, (b) $950{ }^{\circ} \mathrm{C}$ and (c) $1050{ }^{\circ} \mathrm{C}$ for increasing ageing times. 


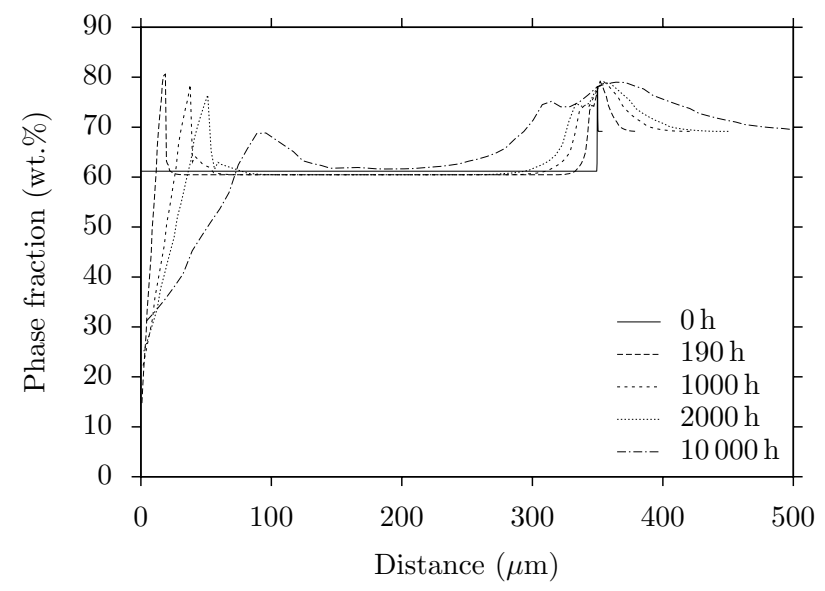

(a)

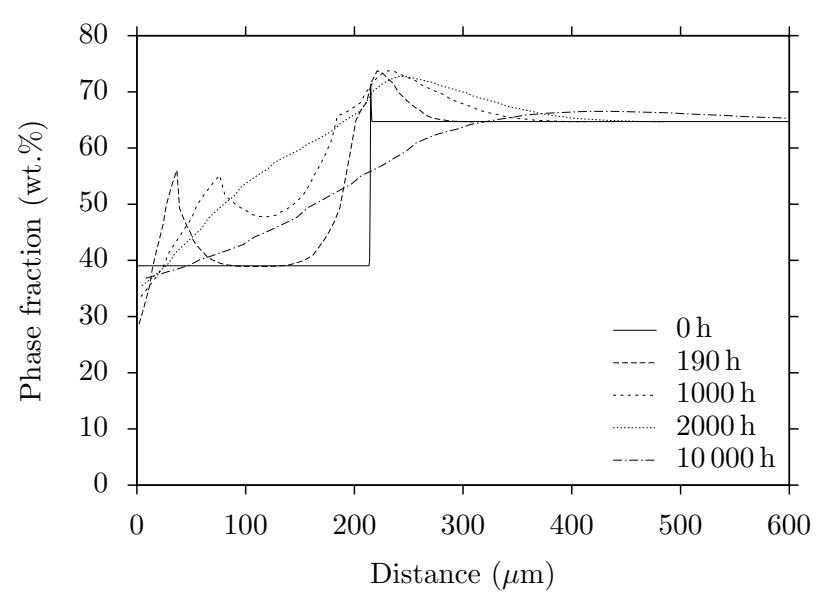

(b)

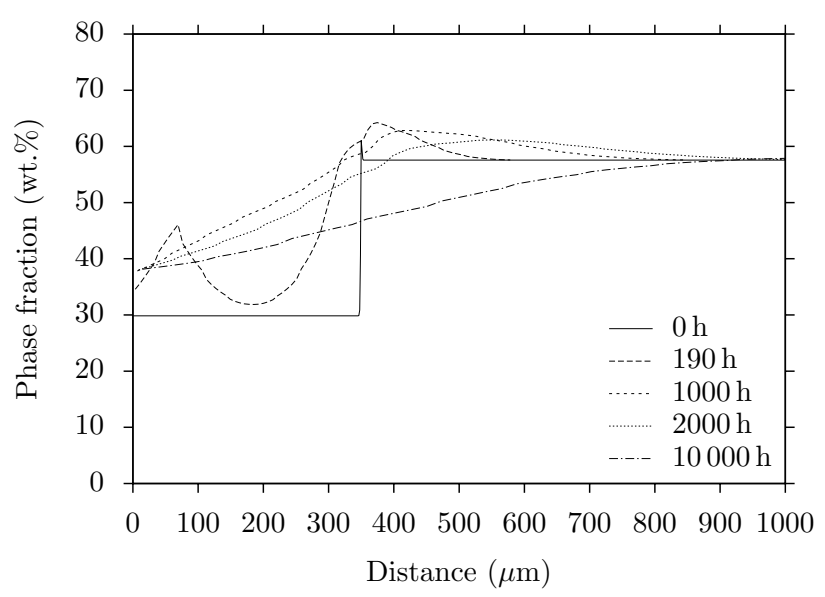

(c)

Figure 9: Simulated $\gamma^{\prime}$ phase profiles across the coating at (a) $850{ }^{\circ} \mathrm{C}$, (b) $950{ }^{\circ} \mathrm{C}$ and (c) $1050{ }^{\circ} \mathrm{C}$ for increasing ageing times. 


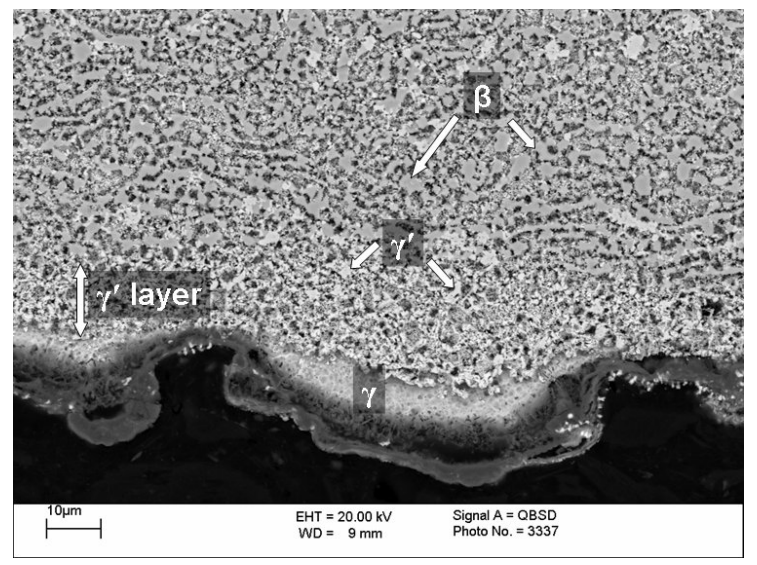

(a)

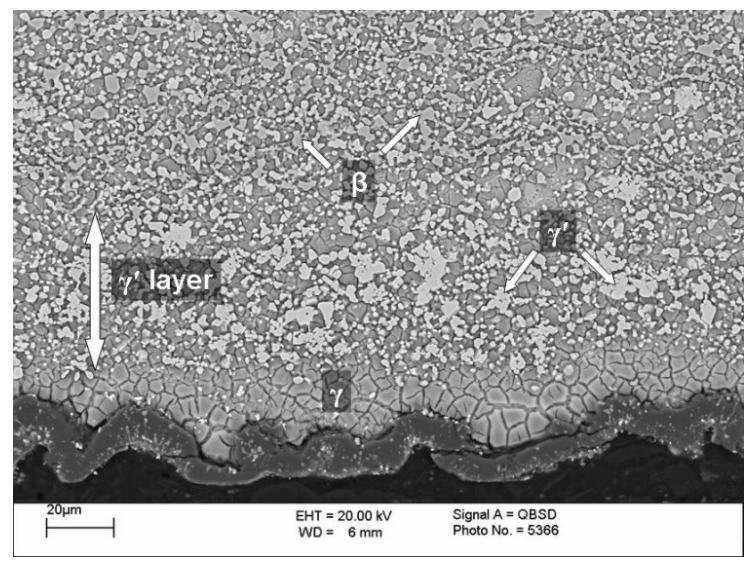

(b)

Figure 10: Scanning electron micrographs showing the depletion of the $\beta$ phase and the formation of a $\gamma^{\prime}$ layer at the coating surface of the NiCoCrAlY coated CMSX4 samples thermally exposed for (a) $2000 \mathrm{~h}$ at $850{ }^{\circ} \mathrm{C}$ and (b) $10000 \mathrm{~h}$ at $950^{\circ} \mathrm{C}$. 
The simulations also predict an increase in the $\gamma^{\prime}$ phase at the coating/substrate interface at all temperatures, which increases in thickness towards the substrate with increasing ageing times. The prediction of a $\gamma^{\prime}$ layer at the coating/substrate interface correlates very well with the experimental observations. A virtually continuous $\gamma^{\prime}$ layer was indeed observed at the coating/substrate interface. The diffusional flux of $\mathrm{Al}$ and $\mathrm{Ni}$, in particular, leads to the transformation of the $\gamma$ phase from the substrate adjacent to the coating into the $\gamma^{\prime}$ layer, and the growth of this layer into the substrate was observed as a result of increased temperature and exposure time, as shown in Figure 11. However, after ageing at $1050{ }^{\circ} \mathrm{C}$ for $10000 \mathrm{~h}$ the simulation predicts a homogenisation of the $\gamma^{\prime}$ phase across the coating and substrate whereas the $\gamma^{\prime}$ layer observed experimentally remains stable for longer ageing times. It is apparent that the prediction by the model at higher temperatures deviates more from the experimental observations. However, at lower temperatures, which are more representative of service conditions, the predictions by the model are more in-line with observations. It is suggested that further improvements of the model, e.g. incorporation of a more accurate oxidation model involving $\mathrm{Cr}$ oxidation, could improve the accuracy of the present model.

\subsubsection{Topologically close packed phases}

Three types of Topologically Close Packed (TCP) phases, namely $\sigma, \mu$ and $P$, which are commonly found in Ni-base superalloy systems, were incorporated in the model. Different combinations of these were predicted by the simulations for each of the temperatures considered. At $850^{\circ} \mathrm{C}$, the substrate was initially predicted to contain $\sim 3.5$ wt. $\%$ of $\mu$ phase and $\sim 1.4$ wt. $\% \sigma$ phase. The coating was predicted to contain high amounts at $\sim 15.5$ wt. $\%$ of $\sigma$ phase; however, no $\sigma$ phase was predicted for the interdiffusion zone on the substrate side. As discussed previously, $\sigma$ phase was not observed experimentally within the coating at $850{ }^{\circ} \mathrm{C}$ but with increased ageing the $\sigma$ phase is indeed predicted within the interdiffusion zone which does correlate well with the experimental observations; see Figure 11(a).

Initially, at $950^{\circ} \mathrm{C}$, no TCP phases are predicted to be present in the coating. With increasing ageing time, a thin layer of $\sigma$ is predicted to form at the coating/substrate interface, which gradually broadens toward the substrate. The simulations also predict that the $\mu$ phase is present at the coating/substrate interface, coexisting with the $\sigma$ phase, although more on the substrate side. The experimental observations were that all three phases, $\sigma, \mu$ and $P$, were present in the interdiffusion-zone at the shorter ageing times, with $\mu$ and $P$ dominating at the longer ageing times; see Figure 11(b).

At $1050{ }^{\circ} \mathrm{C}$, no TCP phases are predicted to be present for the coating bulk composition but a very small fraction $(\sim 0.1 \mathrm{wt} . \%)$ of $P$ phase is predicted in the substrate. However, a sharp peak of $P$ phase is predicted to appear at the bondcoat interface with the substrate, which widens into the substrate and the peak position shifts towards the substrate. This is in broad agreement with experimental observations; Figure 11(c). The $P$ phase was identified at the coating/substrate interface after increased ageing at $1050{ }^{\circ} \mathrm{C}$, but the $\mu$ 


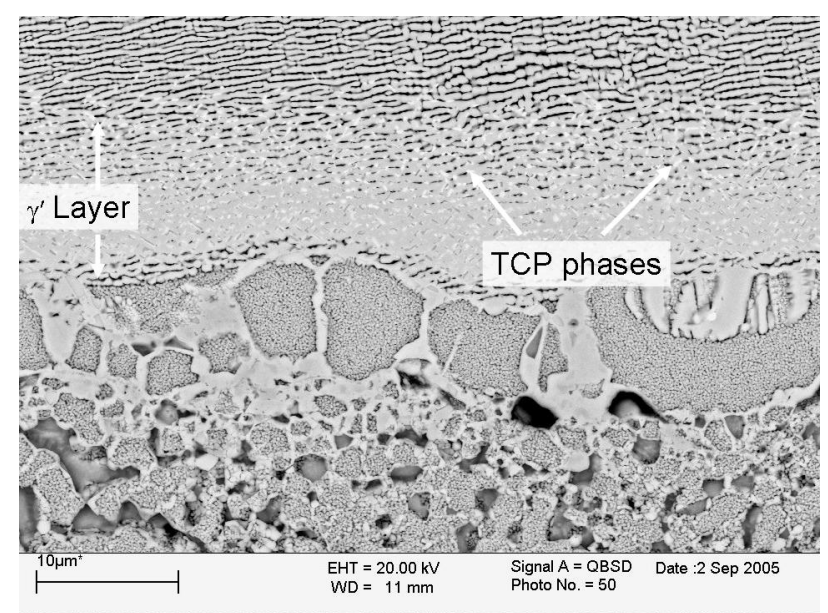

(a)

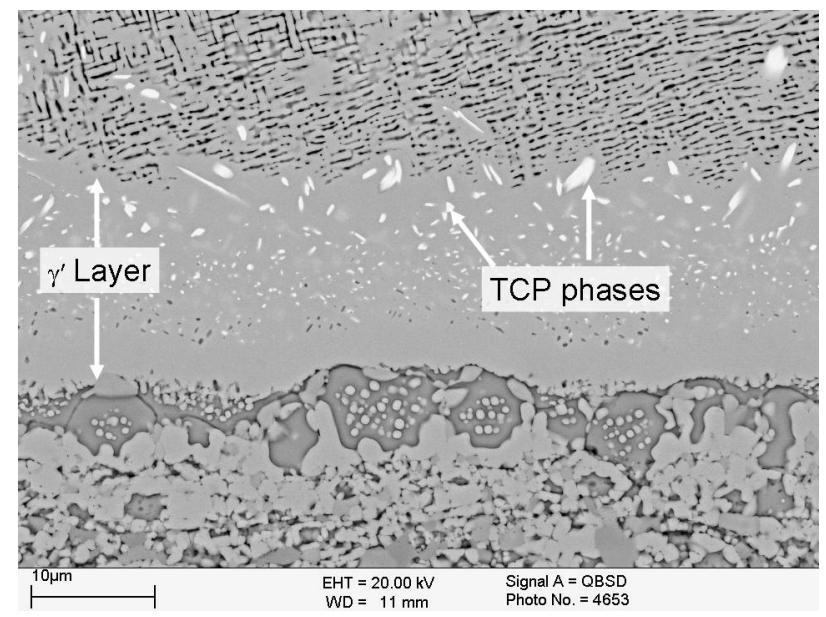

(b)

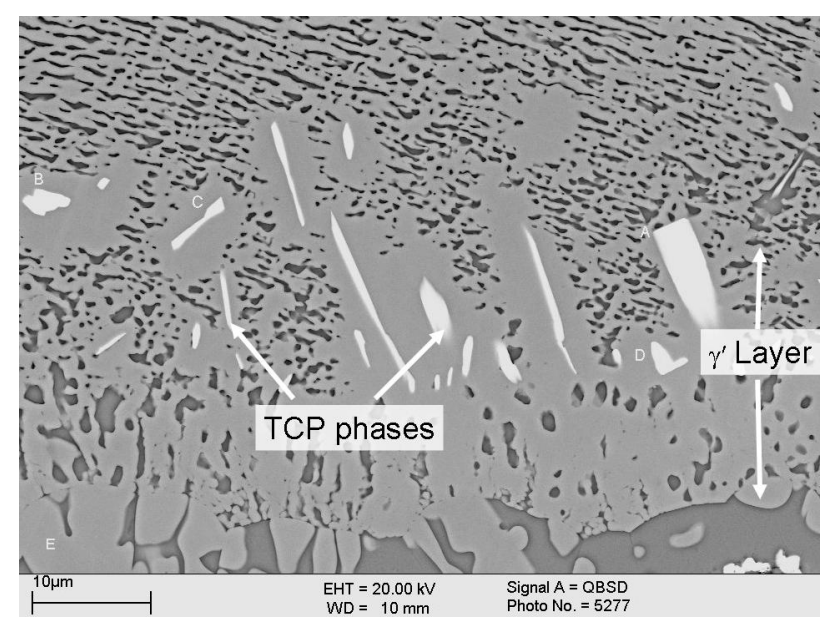

(c)

Figure 11: Scanning electron micrographs showing the growth of the $\gamma^{\prime}$ layer at the coating/substrate interface of the NiCoCrAlY coated CMSX4 samples thermally exposed for (a) $190 \mathrm{~h}$ at $850^{\circ} \mathrm{C}$ (b) $190 \mathrm{~h}$ at $950^{\circ} \mathrm{C}$ and (c) $2000 \mathrm{~h}$ at $1050^{\circ} \mathrm{C}$. 
phase was also identified within the samples extracted for examination in the TEM. It was noted experimentally that the compositions of the $\mu$ and $P$ phase were similar, and that it was difficult to discriminate between the phases on the basis of chemistry alone. It is perhaps therefore not surprising that there are differences in the prediction of the minor amounts of the TCP phases given their apparently close relationships with each other and small differences in their thermodynamic stability.

\subsubsection{Carbide phases}

It has been observed experimentally that minor phase stabilities are very sensitive to $\mathrm{C}$ concentration, and that if there is $\mathrm{C}$ present in the system, then carbides tend to form, both $\mathrm{Cr}$-rich $\mathrm{M}_{23} \mathrm{C}_{6}$ phases, and $\mathrm{Ti} / \mathrm{Ta}$-rich $\mathrm{MC}$ carbides. The model is capable of simulating $\mathrm{C}$ diffusion and predicting carbides that may occur across the coated system. Although there is no carbon specified in the nominal concentration for the coating it may be possible that some carbon is introduced during the application of the coating, and from the furnace environment during ageing. It is also possible for carbon to diffuse from the substrate, which does contain relatively small concentrations of C.

At $850^{\circ} \mathrm{C}, \mathrm{M}_{23} \mathrm{C}_{6}$ carbides are predicted to occur throughout the coating/substrate system and their quantities are sensitive to the amount of $\mathrm{C}$ present in the system; these can exist up to $10000 \mathrm{~h}$ of ageing. It is important to note that a peak in the amount of $\mathrm{M}_{23} \mathrm{C}_{6}$ is predicted at the coating/substrate interdiffusion zone where carbide phases are normally observed in experimental samples. Simulations at $950{ }^{\circ} \mathrm{C}$ predict that a peak of $\mathrm{M}_{23} \mathrm{C}_{6}$ carbides occurs at the interdiffusion-zone. With ageing, the peak broadens slightly towards the substrate and experimental observations which show that a layer of carbide forms in a line in the coating adjacent to the $\gamma^{\prime}$ layer at the coating/substrate interdiffusion zone. At $1050{ }^{\circ} \mathrm{C}$, some $\mathrm{MC}$ carbide is predicted to occur in the substrate along with a peak of $\mathrm{M}_{23} \mathrm{C}_{6}$ in the interdiffusion zone. However, with increasing ageing time, the carbides dissolves quickly.

It has been shown therefore, that there is broad agreement with the experimental observations and the predictions of the model in respect of carbide formation. However, the treatment of carbon diffusion requires closer examination because it appears that once the carbides form in a particular location through the combination of a particular element with the available $\mathrm{C}$, they are very stable, and therefore possibly further $\mathrm{C}$ diffusion through the system should then be prevented.

\section{Conclusions}

A multicomponent diffusion model which is capable of simulating the evolution of microstructure of a coated superalloy system has been developed. The predictions of the model have then been compared extensively with the experimental observations. It is 
shown that in general there is broad agreement with the predictions of the major phases precipitating as a function of time at temperature. The model also has the capability to correctly predict the occurrence of TCP and carbide phases, which are typically observed associated with the interdiffusion zone between the coating and the substrate.

Areas for future development of the model have been highlighted, which include in particular, (i) modelling more accurately the diffusion through the continuous $\gamma^{\prime}$ layer which forms between the coating and the substrate (ii) introducing a way to 'lock' the $\mathrm{C}$ once it has formed carbides in a particular region (iii) the importance of obtaining accurate, concentration dependent diffusion data for all elements and (iv) finally, the need for physically-based, multicomponent alloy oxidation models.

\section{Acknowledgements}

We would like to acknowledge the support of EPSRC through the Supergen 2 programme (GR/S86334/01) and the following companies: Alstom Power Ltd., Chromalloy UK, E.ON UK, Alcoa Howmet Ltd., Doosan Babcock Energy Ltd., National Physical Laboratory (NPL), QinetiQ, Rolls-Royce plc, RWE npower, Sermatech Ltd. and Siemens Industrial Turbomachinery Ltd. for their valuable contributions to the project. We appreciate the support given by the NPL staff in implementing MTDATA in a parallel computation environment. The calculations were performed using the facilities of Loughborough University's High Performance Computing Centre.

\section{References}

[1] James A. Nesbitt. COSIM-a finite-difference computer model to predict ternary concentration profiles associated with oxidation and interdiffusion of overlay-coated substrates. Technical Report NASA/TM-2000-209271, National Aeronautics and Space Administration, Glenn Research Center, August 2000.

[2] Kristian Vinter Dahl and John Hald. Microstructural investigations and modelling of interdiffusion between MCrAlY coating and IN738 superalloy. In Proceedings of EPRI International Conference on Advances in Condition and Remaining Life, Assessment for Fossil Power Plants, 2006.

[3] DICTRA Users Guide version: 20. Div of Physical Metallurgy, Dept of Materials Science and Engineering, Royal Institute of Technology, S-100 44 Stockholm, Sweden, December 1998.

[4] Adolf Fick. Ueber diffusion. Annalen der Physik und Chemie, 94, 1855. 
[5] L. Onsager. Theories and problems of liquid diffusion. Annals New York Academy of Sciences, 46(241):241-265, 1945.

[6] G. D. Smith. Numerical Solution of Partial Differential Equations: Finite Difference Methods. Oxford University Press, second edition, 1985.

[7] J. Crank and P. Nicolson. A practical method for numerical evaluation of solutions of partial differential equations of the heat conducting type. Proceedings of the Cambridge Philosophical Society, XLIII:50-67, 1947.

[8] William H. Press, Saul A. Teukolsky, William T. Vetterling, and Brian P. Flannery. Numerical Recipes in C: The Art of Scientific Computing. Cambridge University Press, Cambridge, 2nd edition, 1992.

[9] S. M. Meier, D. M. Nissley, and K. D. Sheffler. Thermal barrier coating life prediction model development, Phase II Final Report. Technical Report NASA Contractor Report 18911/NAS3-23944, National Aeronautics and Space Administration, NASA Lewis Research Center, July 1991.

[10] E. Y. Lee, D. M. Chartier, R. R. Biederman, and R. D. Sisson. Modelling the microstructural evolution and degradation of M-Cr-Al-Y coatings during high temperature oxidation. Surface and Coatings Technology, 32(1-4):19-39, November 1987.

[11] J. A. Nesbitt. Overlay coating degradation by simultaneous oxidation and coating/substrate interdiffusion. PhD thesis, Michigan Technological University, Houghton, MI, USA, 1983.

[12] R. H. Davies, A. T. Dinsdale, and J. A. Gisby. MTDATA Handbook: Application interface Programming Guide. National Physical Laboratory, Teddington, Middlesex TW11 0LW, UK, October 1998.

[13] Davies R. H., Dinsdale A. T., Gisby J. A., Robinson J. A. J., and Martin S. M. MTDATA-thermodynamics and phase equilibrium software from the National Physical Laboratory. CALPHAD, 26(2):229-271, June 2002.

[14] N. Saunders. Phase diagram calculations for ni-based superalloys. In R. D. Kissinger, M. V. Nathal, D. J. Deye, T. M. Pollock, D. L. Anton, D. A. Woodford, and A. D. Cetel, editors, Proceedings of the Eighth International Symposium on Superalloys (Superalloys 1996), page 101, Seven Springs, Pennsylvania, USA, 1996. The Minerals, Metals \& Materials Society, Warrendale, PA 15086-7528, USA.

[15] W. D. Murray and F. Landis. Numerical and machine solutions of transient heatconduction problems involving melting or freezing part I-method of analysis and sample solutions. Transactions of the American Society of Mechanical Engineers, 81:106-112, may 1959. 
[16] R. A. Swalin and Allan Martin. Solute diffusion in nickel-base substitutional solid solutions. Transactions of the American Institute of Mining and Metallurgical Engineers, pages 567-572, May 1956.

[17] P. L. Gruzin, Iu. A. Polikarpov, and G. B. Fedorov. A study of the diffusion of carbon in nickel and its alloys by means of the radioactive isotope $\mathrm{C}^{14}$. Fizika Metallov i Metallovedenie, 4(1):94-102 (74-80), 1957.

[18] T. Ustad and H. Sorum. Interdiffusion in the Fe-Ni, Ni-Co and Fe-Co systems. Physica Status Solidi A: Applied Research, 20:285-294, 1973.

[19] A. Davin, V. Leroy, D. Coutsouradis, and L. Habraken. Comparison of the diffusion of some substitution elements in nickel and cobalt. Cobalt, 19:51-56, June 1963.

[20] Karunaratne M. S. A and Reed R. C. Interdiffusion of niobium and molybdenum in nickel between 900-1300 degrees c. Diffusion and Defect Data, 237-240:420-425, 2005 .

[21] M. S. A. Karunaratne, P. Carter, and R. C. Reed. Interdiffusion in the face-centred cubic phase of the Ni-Re, Ni-Ta and Ni-W systems between 900 and 1300 celsius. Materials Science and Engineering, A281:229-233, 2000.

[22] N. Komai, M. Watanabe, Z. Horita, T. Sano, and M. Nemoto. Analytical electron microscopy study of Ni/Ni-8 mol\% Ti diffusion couples. Acta Metallurgica, 46(12): 4443-4451, July 1998.

[23] T. Ikeda, A. Almazouzi, H. Numakura, M. Koiwa, W. Sprengel, and H. Nakajima. Interdiffusion in $\mathrm{Ni}_{3} \mathrm{Al}$. Diffusion and Defect Data. Part A: Defect and Diffusion Forum, 143-147:275-278, 1997.

[24] Y. Minamino, S. B. Jung, T. Yamane, and K. Hirao. Diffusion of cobalt, chromium and titanium in Ni/Ni $\mathrm{Ni}_{3} \mathrm{Al}$. Metallurgical \& Materials Transactions A, 23A:27832790, October 1992.

[25] St. Frank, U. Södervall, and Chr. Herzig. Self- and impurity diffusion of Ni, Ga, Ge, $\mathrm{Ti}, \mathrm{Nb}$ and $\mathrm{B}$ in the $\mathrm{L}_{2}$-type intermetallic compound $\mathrm{Ni}_{3} \mathrm{Al}$. Diffusion and Defect Data. Part A: Defect and Diffusion Forum, 143-147:245-250, 1997.

[26] Hua Wei, Xiaofeng Sun, Qi Zheng, Hengrong Guan, and Zhuangqi Hu. Estimation of interdiusivity of the NiAl phase in NiAl binary system. Acta Materialia, 52: 2645-2651, 2004.

[27] Ryusuke Nakamura, Koichi Takasawa, Yoshihiro Yamazaki, and Yoshiaki Iijima. Single-phase interdiffusion in the B2 type intermetallic compounds NiAl, CoAl and FeAl. Intermetallics, 10:195-204, 2002.

[28] A. Engström, L. Höglund, and J. Ågren. Computer simulation of diffusion in multiphase systems. Metallurgical \& Materials Transactions A, 25A:1127-1133, 1994. 
[29] C. T. Sims, N. S. Stoloff, and W. C. Hagel, editors. Superalloys II: High-temperature Materials for Aerospace and Industrial Power. Wiley-Interscience Publication. John Wiley \& Sons, New York, 1987.

[30] Kiyotaka Matsuura, Toshiki Kitamutra, and Masayuki Kudoh. Microstructure and mechanical properties of NiAl intermetallic compound synthesized by reactive sintering under pressure. Journal of Materials Processing Technology, 63(1-3):298-302, January 1997.

[31] Jie Meng, Chengchang Jia, and Qing He. Fabrication of Ni3Al by hot pressing from element powders. Rare Metals, 26(3):222-225, June 2007.

[32] L. Peichl and G. Johner. High-temperature behavior of different coatings in highperformance gas-turbines and in laboratory tests. Journal of Vacuum Science \& Technology A, 4(6):2583-2592, Nov-Dec 1986. 